\title{
Assessment of Risk Factors of Noncommunicable Diseases among Semiurban Population of Kavre District, Nepal
}

\author{
Punjita Timalsina $\mathbb{D}^{1}$ and Regina Singh $\mathbb{D}^{2}$ \\ ${ }^{1}$ Maharajgunj Nursing Campus, Institute of Medicine, Tribhuvan University, Maharajgunj, Kathmandu 44600, Nepal \\ ${ }^{2}$ School of Nursing, Kathmandu Medical College Affiliated to Kathmandu University, Duwakot, Bhaktapur 44800, Nepal \\ Correspondence should be addressed to Punjita Timalsina; punjita.timalsina@mnc.tu.edu.np
}

Received 18 January 2021; Revised 19 April 2021; Accepted 31 May 2021; Published 8 June 2021

Academic Editor: Marco Dettori

Copyright ( $) 2021$ Punjita Timalsina and Regina Singh. This is an open access article distributed under the Creative Commons Attribution License, which permits unrestricted use, distribution, and reproduction in any medium, provided the original work is properly cited.

\begin{abstract}
Noncommunicable diseases (NCDs) are posing a great threat to mankind. Timely identification, prevention, and control of common risk factors help to reduce the burden of death from NCDs. These risk factors are also closely related to lifestyle changes. This study aimed to assess the prevalence of risk factors of NCDs among semiurban population of Kavre district. Communitybased cross-sectional study design using the multistage sampling method was used to select 456 respondents. Data were collected using WHO's STEPS instruments 1 and 2. Four behavioural risk factors, i.e., current tobacco use, harmful alcohol use, physical inactivity, and inadequate servings of fruits and vegetables and two metabolic risk factors, i.e., abdominal obesity and hypertension were included in the study. The study revealed that more than one-third $(36.0 \% ; 43.0-52.2 \%)$ were current tobacco users, nearly one-sixth $(15.8 \% ; 12.7-19.4 \%)$ consumed alcohol harmfully, most of all did not have adequate servings of fruits and vegetables (95.8\%; 93.6-97.3\%), nearly two-thirds have abdominal obesity $(62.1 \%$; $57.5-66.4 \%)$, and more than one-fifth of population had hypertension $(22.1 \% ; 18.6-26.2 \%)$. Only $1.1 \%$ respondents were free from risk factors, while $78.5 \%, 46.1 \%, 14.5 \%$, and $1.8 \%$ had two, three, four, and five risk factors, respectively. The co-occurrence of three or more risk factors was associated with increasing age (AOR ranging 4.7-10.9), male sex $(\mathrm{AOR}=3.9(2.4-6.3) ; p<0.001)$, and illiterate respondents $(\mathrm{AOR}=1.7$ $(1.0-2.9) ; p=0.038)$. The study concludes that almost all adults residing in semiurban areas of Kavre district have at least one or more risk factors, and nearly half of them have three or more risk factors. This suggests appropriate preventive approaches to be focused on younger age groups, male sex, and illiterate population to reduce the prevalence of NCDs in the near future.
\end{abstract}

\section{Introduction}

Noncommunicable diseases (NCDs) have become a medical and financial challenge in the 21 st century $[1,2]$. Four major NCDs (cardiovascular diseases, cancer, diabetes, and chronic respiratory diseases including asthma and COPD) are responsible for the maximum proportion of NCD deaths which share common risk factors of physical inactivity, unhealthy diet, tobacco use, and alcohol use [3-6].

Currently, NCDs accounts for more than $80 \%$ of premature deaths in developing countries [7-9]. Recent national report of Nepal NCDI Poverty Commission also revealed that the burden of NCDs has more than doubled over the past 25 years [10]. Being largely preventable, these deaths can be greatly reduced by proper intervention strategies [11].

Since most of the studies regarding NCDs have been focused either on urban or rural settings, this study was conducted to picture the prevalence of risk factors in semiurban areas of Kavre district. This study would be a prototype of villages near cities of Nepal.

\section{Materials and Methods}

A community-based cross-sectional descriptive study was carried out from December 14, 2017, to January 19, 2018, in a semiurban area of Kavre district. Approval for the implementation of the study was sought from the Institutional 
Review Committee (IRC) of Kathmandu University (approval number 31/17). Permission to conduct the study was obtained from District Health Office, Dhulikhel, Kavre, and then from municipalities and ward offices. The study' purpose, issues of confidentiality, anonymity, and respondents' right to withdraw from the study at any stage without notice were explained to all respondents before participation in the study. Respondents were also informed to consult health centers if any queries were encountered. Completed questionnaires were compiled and stored in a locked place by the principal researcher.

Multistaged random sampling technique was used. Target population was all adults aged 18-64 years residing in semiurban areas of Kavre district. Inclusion criteria included those who were living in the place of residence for at least six months. All six municipalities of Kavre district were included in the study. From the newly declared wards of each municipality which was previously a VDC, one ward was chosen randomly (Figure 1). The number of samples to be taken from each ward was calculated following the probability proportional to size (PPS) sampling method. In the ward, a household was chosen by following systematic random sampling. Finally, at the household level, an eligible respondent was selected using a simple random sampling technique following Kish grid.

Sample size was determined by applying the following formula:

$$
n=\frac{Z_{\alpha}^{2} p q}{d^{2}}
$$

where $Z_{\alpha}$ at $95 \%$ confidence interval is $1.96, p$ is the proportion, $q=(1-p)$, and $d$ is the error taken at $20 \%$ of prevalence).

Using equation (1), we get

$$
n=\frac{1.96^{2} \times 0.174 \times 0.826}{0.0348^{2}}=455.9 \text { respondents } \cong 456 \text { respondents, }
$$

where $p$ was taken as $17.4 \%$ as Nepal STEPS survey 2013 [4].

Thus, the sample size was 456 respondents.

According to the PPS sampling method, the following respondents were selected from each municipality:

(i) Panchkhal ward number $13(12.4 \%)=56$ respondents out of total 461 households

(ii) Namobuddha ward number $11(16.1 \%)=74$ respondents out of total 600 households

(iii) Dhulikhel ward number $1(12.3 \%)=56$ respondents out of total 460 households

(iv) Mandan ward number $11(18 \%)=82$ respondents out of total 667 households

(v) Panauti ward number $2(20.1 \%)=92$ respondents out of total 751 households

(vi) Banepa ward number $4(21.1 \%)=96$ respondents out of total 785 households
Data were collected using the standardized WHO STEPwise approach to Surveillance (STEPS) approaches 1 and 2, translated in Nepali language. STEP 1 data were collected by using face-to-face interview in which data were recorded in Open Data Kit (ODK) [12] toolkit. STEP 2 data included anthropometric measurements of height, weight, waist circumference, and hip circumference. Individual's height was measured without footwear and any clothing on head. Bodyweight was measured by placing a weighing machine at the smooth surface and was recorded in kilogram. Respondents were requested to wear light clothes without footwear during weighing. Waist and hip circumference measurement was conducted in a private place with a measuring tape. Waist circumference was taken at the midpoint between the lower margin of the last palpable rib and the top of the iliac crest, in the standing position without clothing and directly over the skin. The finding was recorded in centimetres. The hip circumference was taken in centimetres at maximum circumference over the buttocks horizontally. Blood pressure was measured two times at an interval of 5 minutes, and the average value of the measurements was used for the analysis. Blood pressure was taken from the left arm keeping the cuff at the same level as the heart during the procedure with elbow support. To attain the correct measurement, the respondent was not allowed to talk during the procedure, the bladder was emptied, and no coffee before and during the measurement was allowed.

After the collection of data, the data were transferred to Excel each day. SPSS version 22.0 was used for descriptive and inferential statistics. Further report was submitted to the respective wards, and a task completion letter was obtained.

\section{Results}

3.1. Sociodemographic Characteristics of the Respondents. Among the total 456 respondents, the mean age was 42.6 years, around two-fifths $(43.0 \%)$ were male, three-fifths (57.0\%) were female, nearly two-fifths were illiterate, and more than one-fifth $(22.1 \%)$ belonged to the lowest quintile (Table 1).

3.2. Behavioural and Metabolic Risk Factors of NCDs. Nearly half of the participants $(47.6 \%)$ have ever used tobacco in their lifetime, and more than one-third (36.0\%) of participants were current users of tobacco. The most commonly used type of tobacco was cigarette smoking $(87.8 \%)$, followed by chewing tobacco $(21.3 \%)$. The mean age of initiation of tobacco among males was 18.97 years and females was 15.11 years. Nearly half of the participants (48.7\%) were lifetime abstainers, while others had used alcohol sometime in their life. More than one-third of the participants $(35.1 \%)$ were current drinkers. Among total participants, one-sixth were harmful users of alcohol (15.8\%), while among current drinkers, nearly half (45\%) were harmful alcohol users. Less than one-tenth of the 


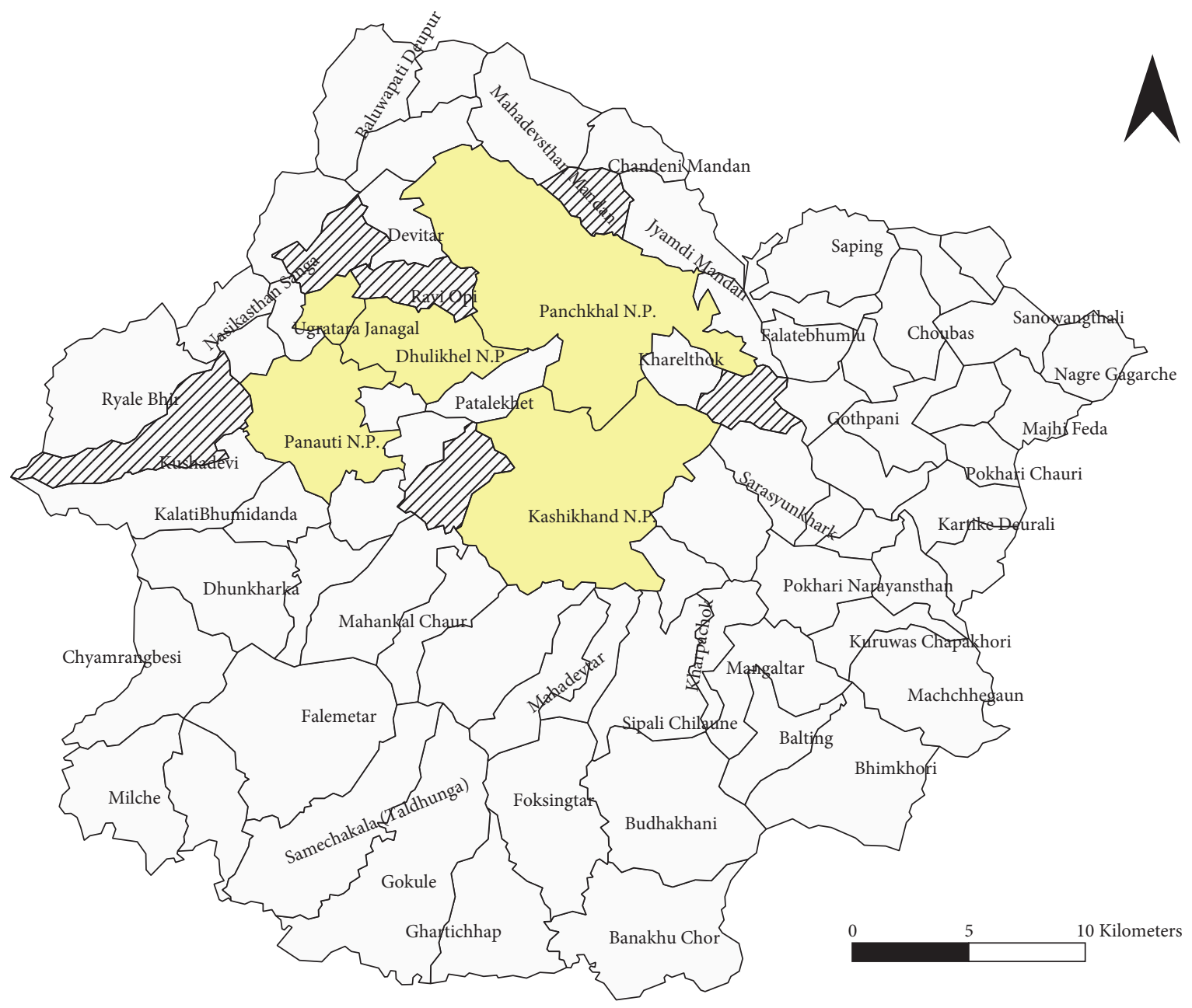

$\square Z \triangle$ Study Area

$\square$ Municipallities

Village development committees

FIGURE 1: Geographical map of Kavre showing the selected semiurban areas (source: available from http://ddckavre.gov.np/en/ddc-kavre/).

TABle 1: Sociodemographic characteristics of the respondents $(n=456)$.

\begin{tabular}{|c|c|c|c|c|}
\hline Variables & Male, $n(\%)$ & Female, $n(\%)$ & Total, $n(\%)$ & $P$ value \\
\hline \multicolumn{5}{|l|}{ Age group (in years) } \\
\hline $18-24$ & $18(9.2)$ & $34(13.1)$ & $52(11.4)$ & \multirow{5}{*}{0.439} \\
\hline $25-34$ & $30(15.3)$ & $45(17.3)$ & $75(16.5)$ & \\
\hline $35-44$ & $51(26.0)$ & $74(28.4)$ & $125(27.4)$ & \\
\hline $45-54$ & $50(25.5)$ & $54(20.8)$ & $104(22.8)$ & \\
\hline $55-64$ & $47(24.0)$ & $53(20.4)$ & $100(21.9)$ & \\
\hline Age (in years), mean \pm SD & $44.0 \pm 12.6$ & $41.5 \pm 13.1$ & $42.6 \pm 12.9$ & 0.434 \\
\hline Gender & $196(43.0)$ & $260(57.0)$ & $456(100.0)$ & - \\
\hline \multicolumn{5}{|l|}{ Education } \\
\hline Illiterate & $34(17.3)$ & $144(55.4)$ & $178(39.0)$ & \multirow{2}{*}{$<0.001$} \\
\hline Literate & $162(82.7)$ & $116(44.6)$ & $278(61.0)$ & \\
\hline \multicolumn{5}{|c|}{ Monthly household income by quintile groups } \\
\hline Fifth quintile & $36(18.4)$ & $36(13.8)$ & $72(15.8)$ & \multirow{5}{*}{0.770} \\
\hline Fourth quintile & $55(28.1)$ & $74(28.5)$ & $129(28.3)$ & \\
\hline Third quintile & $42(21.4)$ & $60(23.1)$ & $102(22.4)$ & \\
\hline Second quintile & $21(10.7)$ & $31(11.9)$ & $52(11.4)$ & \\
\hline First quintile & $42(21.4)$ & $59(22.7)$ & $101(22.1)$ & \\
\hline
\end{tabular}


TABLE 2: Behavioural and metabolic risk factors of NCDs $(n=456)$.

\begin{tabular}{|c|c|c|}
\hline Risk factors & $n(\%)$ & $95 \% \mathrm{CI}$ \\
\hline \multicolumn{3}{|l|}{ Behavioural risk factors } \\
\hline \multicolumn{3}{|l|}{ Tobacco use } \\
\hline Ever users & $217(47.6)$ & $43.0-52.2$ \\
\hline Current users & $164(36.0)$ & $31.7-40.5$ \\
\hline Daily users & $161(35.3)$ & $31.1-39.8$ \\
\hline \multicolumn{3}{|l|}{ Alcohol use } \\
\hline Lifetime abstainers & $222(48.7)$ & $44.1-53.3$ \\
\hline Past 12 months abstainer & $54(11.8)$ & $9.2-15.1$ \\
\hline Drank only in past 12 months & $20(4.4)$ & $2.9-6.7$ \\
\hline Current drinkers & $160(35.1)$ & $30.8-39.6$ \\
\hline \multicolumn{3}{|l|}{ Among current drinkers $(n=160)$} \\
\hline Category I drinker & $55(34.4)$ & $27.5-42.0$ \\
\hline Category II drinker & $33(20.6)$ & $15.1-27.5$ \\
\hline Category III drinker/harmful alcohol use & $72(45.0)$ & $37.5-52.7$ \\
\hline Inadequate servings of fruits and vegetables & $437(95.8)$ & $93.6-97.3$ \\
\hline \multicolumn{3}{|l|}{ Level of physical activity } \\
\hline High & $383(84.0)$ & $80.3-87.1$ \\
\hline Moderate & $39(8.6)$ & $6.3-11.5$ \\
\hline Low & $34(7.5)$ & $5.4-10.2$ \\
\hline \multicolumn{3}{|l|}{ Metabolic risk factors } \\
\hline Raised blood pressure & $101(22.1)$ & $18.6-26.2$ \\
\hline Abdominal obesity (waist-hip ratio) & $283(62.1)$ & $57.2-66.3$ \\
\hline
\end{tabular}

participants were physically inactive (7.5\%) (Table 2). The study has also revealed that females performed more physical activity compared to males. Mean hours spent in sitting on average per day was 3.96 hours. Furthermore, the majority of the participants (95.8\%) took inadequate, i.e., less than 5 servings of fruits and/or vegetables on average per day. The mean number of servings of fruits and/or vegetables on average per day was 2.5 servings (Table 3 ).

History of hypertension was present in nearly one-sixth of the participants (17.1\%), while hypertension was present in more than one-fifth of the participants $(22.1 \%)$. Health risk according to abdominal obesity was also present in twothirds $(62.1 \%)$ of the participants (Table 2$)$. The mean waisthip ratio for males was 0.939 and for females was 0.855 , which showed that the mean value is above the cutoff point for abdominal obesity (Table 3 ).

3.3. Co-Occurrence of Risk Factors. Four biological and three behavioural risk factors were included in this study. It was found that only $1.1 \%$ of the population was totally free from these seven risk factors. Nearly half of the respondents had three or more risk factors $(46.1 \%)$. After this, respondents with four or more risk factors gradually dropped to $14.5 \%$ (Figure 2). The mean number of risk factors was 2.78 risk factors (Table 3 ).

The co-occurrence of three or more risk factors was significantly associated with increasing age (adjusted odds ratio ranging 4.7-10.9), where males were at 3 times more risk of having combined risk factors compared to females. Similarly, illiterates had 1.7 times more risk of having combined risk factors compared to literates (Table 4).

\section{Discussion}

The rate of current tobacco use is double than national data, i.e., $18.5 \%$ but lower than NDHS surveillance data $(39.8 \%)$ $[4,13]$. This might be due to inclusion of all age groups in NDHS survey and only adults in STEPS survey. Similar study in squatter of Kathmandu valley reported $39.81 \%$ current drinkers [14]. Another study at Sindhupalchowk revealed prevalence of alcohol drinking to be $62.9 \%$ [15]. These findings are similar to findings of this study.

The study among adults of Duwakot showed low physical activity among $43.3 \%$ [16]. Another study at Kathmandu also reported low physical activity among $17.6 \%$ [17]. Few participants with low physical activity in this study might be due to semiurban area of Kavre district still being agricultural region which demands more physical activity which is correlated with national STEPS survey, which revealed low physical activity only in $3.5 \%$ of participants [4].

STEPS survey also revealed overweight among 17.7\% and obesity among $4 \%$ of study participants [4]. This variation might be due to inclusion of rural regions also where physical activity is adequate. Demographic survey of Nepal also revealed overweight among $22 \%$ female and $17 \%$ of males [13]. These findings are similar to findings from this study. Mean waist-hip ratio was 0.9 for both male and female in national STEPS survey [4]. Study in Bharatpur revealed abdominal obesity among $81.7 \%$ of males and $94.1 \%$ of females [18]. This variation might be due to Bharatpur being more urban region.

STEPS survey concluded only $0.4 \%$ of sample to be free from risk factors [4]. Another evidence of cumulative risk 
TABLE 3: Summary of risk factors of NCDs $(n=456)$.

\begin{tabular}{|c|c|c|c|c|}
\hline Risk factors & $\begin{array}{c}\text { Male } \\
\text { Median (IQR) }\end{array}$ & $\begin{array}{c}\text { Female } \\
\text { Median (IQR) }\end{array}$ & $\begin{array}{c}\text { Total } \\
\text { Median (IQR) }\end{array}$ & $P$ value \\
\hline Standard drinks, number/occasion & $5.7(2.6-12.8)$ & $3.25(1.4-5.85)$ & $5.3(2.0-10.6)$ & 0.011 \\
\hline Fruits/vegetables, servings/day & $2(2-3)$ & $2(2-3)$ & $2(2-3)$ & 0.632 \\
\hline Physical activity, MET minutes/week & $7340(2405-13860)$ & $8400(5400-12600)$ & $8400(5040-12870)$ & 0.127 \\
\hline Body mass index & $23.8(21.9-26.5)$ & $23.8(21.4-27.2)$ & $23.8(21.6-27.0)$ & 0.655 \\
\hline Waist circumference $(\mathrm{cm})$ & $87(79.2-94.0)$ & $78.5(70-88)$ & $82(82-90)$ & $<0.001$ \\
\hline Waist-hip ratio & $0.94(0.89-0.98)$ & $0.86(0.80-0.91)$ & $0.89(0.83-0.94)$ & $<0.001$ \\
\hline $\mathrm{BP}$, systolic $(\mathrm{mm}$ of $\mathrm{Hg})$ & $110(100-130)$ & $105(95-120)$ & $110(95-120)$ & 0.001 \\
\hline $\mathrm{BP}$, diastolic ( $\mathrm{mm}$ of $\mathrm{Hg}$ ) & $75(66.25-85)$ & $70(60-80)$ & $70(65-80)$ & 0.016 \\
\hline
\end{tabular}

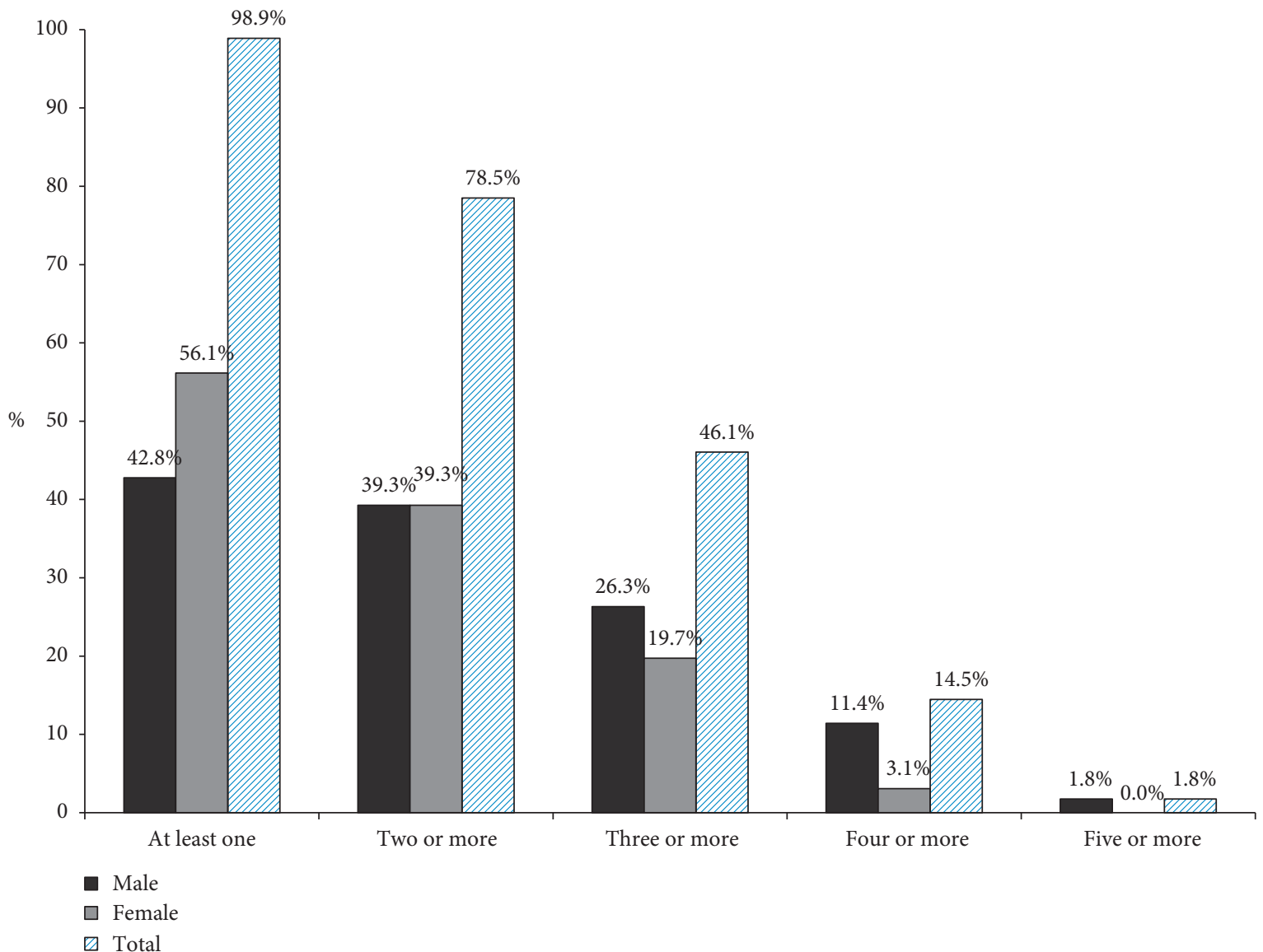

FIGURE 2: Co-occurrence of risk factors of NCDs by gender $(n=456)$.

TABLE 4: Association of co-occurrence of three or more risk factors with sociodemographic variables.

\begin{tabular}{|c|c|c|c|c|}
\hline Sociodemographic variables & OR $(95 \% \mathrm{CI})$ & $P$ value & AOR $(95 \% \mathrm{CI})$ & $P$ value \\
\hline \multicolumn{5}{|l|}{ Age } \\
\hline $18-24$ years & Reference & & Reference & \\
\hline $25-34$ years & $5.0(1.8-14.1)$ & 0.002 & $4.7(1.6-13.7)$ & 0.005 \\
\hline $35-44$ years & $7.4(2.7-19.8)$ & $<0.001$ & $6.6(2.3-18.5)$ & $<0.001$ \\
\hline $45-54$ years & $13.9(5.1-37.8)$ & $<0.001$ & $10.9(3.8-31.3)$ & $<0.001$ \\
\hline $55-64$ years & $15.3(5.6-42.0)$ & $<0.001$ & $10.9(3.7-32.1)$ & $<0.001$ \\
\hline \multicolumn{5}{|l|}{ Sex } \\
\hline Female & Reference & & Reference & \\
\hline Male & $3.0(2.0-4.4)$ & $<0.001$ & $3.9(2.4-6.3)$ & $<0.001$ \\
\hline Educational status & & & & \\
\hline
\end{tabular}


TABLE 4: Continued.

\begin{tabular}{|c|c|c|c|c|}
\hline Sociodemographic variables & OR $(95 \% \mathrm{CI})$ & $P$ value & AOR $(95 \% \mathrm{CI})$ & $P$ value \\
\hline Literate & Reference & & Reference & \\
\hline Illiterate & $1.4(0.9-2.1)$ & 0.054 & $1.7(1.0-2.9)$ & 0.038 \\
\hline \multicolumn{5}{|l|}{ Household income } \\
\hline Richest (20\%) & Reference & & Reference & \\
\hline Second quintile & $0.7(0.4-1.3)$ & 0.243 & $0.7(0.3-1.4)$ & 0.309 \\
\hline Third quintile & $0.5(0.2-0.9)$ & 0.031 & $0.5(0.3-1.0)$ & 0.056 \\
\hline Fourth quintile & $0.8(0.4-1.7)$ & 0.606 & $0.9(0.4-1.9)$ & 0.767 \\
\hline Poorest $(20 \%)$ & $0.9(0.5-1.8)$ & 0.969 & $0.9(0.5-1.8)$ & 0.813 \\
\hline
\end{tabular}

factors in Uganda revealed that most participants exhibited at least two risk factors supported by mean number of risk factor of our study [19]. These all findings suggest that burden of combined risk factors of noncommunicable is in increasing trend. Similar study in Bangladesh regarding clustering of three or more risk factors revealed association of clustering of risk factors with age, male sex, and educational level [8]. This supports the association found in our study.

\section{Conclusions}

The prevalence of risk factors of noncommunicable disease is high in semiurban setting of Kavre district. Additionally, there exist gender differences in the prevalence of risk factors, with more risk factors occurring in males compared to females. Moreover, the risk factor is more among illiterate than literate. Therefore, it is necessary to minimize the burden of growing noncommunicable disease epidemic in semiurban areas of Kavre district. This can be done by conducting awareness programs regarding NCD risk factors continuously to bring behaviour change. This should also be focused on early age because the risk of noncommunicable diseases is fairly low in this age group. Since the initiation of smoking and alcohol use is at adolescence, smoking cessation and awareness campaigns should be targeted to these groups to prevent the adoption of risk behaviours. In addition, persons could be informed of body mass index and waist circumference and avoid pot belly. Additionally, appropriate plans can be drafted in new urban and federal health policies.

\section{Data Availability}

The datasets used and/or analysed during this study are available from the corresponding author upon request.

\section{Conflicts of Interest}

The authors declare that there are no conflicts of interest.

\section{Acknowledgments}

The authors are highly obliged to all participants of the study and local leaders who facilitated the conduction of the study. They also acknowledge that it is their great pleasure to convey gratitude to statistician Late Dr. Kedar Manandhar for necessary support during data analysis and correction. This study was financially supported by University Grant Commission (UGC) of Nepal, in the form of Masters Research Support 2074/75 (award number MRS/74_75/HS_4).

\section{References}

[1] S. Khanal, L. Veerman, S. Hollingworth, and L. Nissen, "Shift in disease burden from communicable to non-communicable diseases: aiming to achieve Universal Health Coverage in Nepal," Perspectives in Public Health, vol. 135, no. 4, pp. 177-178, 2015.

[2] World Health Organization, Package of Essential Non-communicable Disease Interventions for Primary Health Care in Low-Resource Settings, World Health Organization, Geneva, Switzerland, 2010, https://www.who.int/nmh/publications/ essential_ncd_interventions_lr_settings.pdf.

[3] World Health Organization, Global Status Report on Noncommunicable Diseases 2014, World Health Organization, Geneva, Switzerland, 2014, https://reliefweb.int/report/world/ global-status-report-noncommunicable-diseases-2014-attainingnine-global.

[4] K. K. Aryal, S. Neupane, S. Mehata et al., Non Communicable Diseases Risk Factors: STEPS Survey Nepal 2013, Nepal Health Research Council, Kathmandu, Nepal, 2014, http://nhrc.gov. np/wp-content/uploads/2017/02/noncommunicable-diseasereport_2012_2013.pdf.

[5] M. D. Bhattarai, "Epidemic of non-communicable diseases and its control," Kathmandu University Medical Journal, vol. 10, no. 38, pp. 1-3, 2012.

[6] World Health Organization, Highlights from the WHO Global Conference on NCDs: Enhancing Policy Coherence to Prevent and Control Non-communicable Diseases, World Health Organization, Geneva, Switzerland, 2017, https://www.who.int/ conferences/global-ncd-conference/en/.

[7] World Health Organization, Action Plan for the Prevention and Control of Non-communicable Diseases, 2013-2020. New Dehli, India, Regional Office for South-East Asia, World Health Organization, Geneva, Switzerland, 2013, https://www.iccpportal.org/sites/default/files/resources/sea-ncd-89\% 28reduced\%29.pdf.

[8] M. M. Zaman, M. R. Bhuiyan, M. N. Karim et al., "Clustering of non-communicable diseases risk factors in Bangladeshi adults: an analysis of steps survey 2013," BMC Public Health, vol. 15, no. 1, p. 659, 2015.

[9] World Health Organization, Non-Communicable Diseases Progress Monitor, World Health Organization, Geneva, 
Switzerland, 2017, https://apps.who.int/iris/bitstream/handle/ 10665/258940/9789241513029-eng.pdf?sequence $=1$.

[10] The Nepal NCDI Poverty Commission, An Equity Initiative to Address Non-communicable Diseases and Injuries, The Nepal NCDI Poverty Commission, Kathmandu, Nepal, 2018, https:// static1.squarespace.com/static/55d4de6de4b011a1673a40a6/ t/5abe85111ae6cfa98183e7a9/1522435346791/Nepal+NCDI+ Poverty+Commission+National+Report+2018.pdf.

[11] World Health Organization, Status of the Health-Related SDGs: Monitoring Health for the SDGs, World Health Organization, Geneva, Switzerland, 2017, http://www.who.int/ gho/publications/world_health_statistics/2017/EN_ WHS2017_Part2.pdf?ua=1.

[12] W. Box, Open Data Kit: Magnifying Human Resources through Technology, pp. 3-4, ODK Media, Inc., Fullerton, CA, USA, 2008, https://docs.opendatakit.org.

[13] Ministry of Health and Population, New Era, ICF International Demographic and Health Survey Program, Ministry of Health, Kathmandu, Nepal, 2016, https://www.dhsprogram. com/pubs/pdf/fr336/fr336.pdf.

[14] P. Thapa, S. R. Mishra, A. R. Pandey et al., "Prevalence and predictors of alcohol consumption among the squatter of Kathmandu valley," Journal of Nepal Health Research Council, vol. 14, no. 1, pp. 18-26, 2016, http://jnhrc.com.np/index.php/ jnhrc/article/view/720/524.

[15] N. Manandhar, "Study on associated risk factors of hypertension at sipaghat of sindhupalchowk district, Nepal," Nepalese Journal of Statistics, vol. 1, pp. 73-82, 2017.

[16] A. Vaidya and A. Krettek, "Physical activity level and its sociodemographic correlates in a peri-urban Nepalese population: a cross-sectional study from the Jhaukhel-Duwakot health demographic surveillance site," International Journal of Behavioural Nutrition and Physical Activity, vol. 11, no. 1, p. 39, 2014.

[17] A. Gautam, D. N. Bhatta, and U. R. Aryal, "Diabetes related health knowledge, attitude and practice among diabetic patients in Nepal," BMC Endocrine Disorders, vol. 15, no. 1, p. 25, 2015.

[18] M. Pradhan, "Clinical study of obesity and associated morbidities in patients admitted to College of Medical Sciences Teaching-Hospital, Bharatpur," Journal of Medical SciencesNepal, vol. 11, no. 3, pp. 16-19, 2015.

[19] R. Wesonga, D. Guwatudde, S. K. Bahendeka, G. Mutungi, F. Nabugoomu, and J. Muwonge, "Burden of cumulative risk factors associated with non-communicable diseases among adults in Uganda: evidence from a national baseline survey," International Journal for Equity in Health, vol. 15, no. 1, p. 195, 2016. 